to the casium chloride-type structure ${ }^{1}$, and it is to be expected that the transitions in sodium fluoride, bromide and iodide are similar.

Cart W. F. T. Pistoridus

Chemical Physics Group,

National Physical and Chemical Research Laboratories, South African Council for Scientific and Industrial Research, Pretoria.

'Evdokimova, V. V., and Vereshchagin, L. F., Fiz. Tverd. Tela, 4, 1965 (1962) [Transl. in Sov. Phys. Solid State, 4, 1438 (1962/3)].

2 Pistorius, C. W. F. T., Nature, 201, 1321 (1964).

${ }^{3}$ Bridgman, P. W., Proc. Amer. Acad. Arts Sci., 72, 45 (1937).

Kennedy, G. C., and Newton, R. C., Solids under Pressure (McGraw-Hill Book Co., Inc., New York, 1963).

- Jayaraman, A., Klement, W., Newton, R. C., and Kennedy, G. C., J. Phys. 7 (1963).

- Pistorius, C. W. F. T., J. Phys. Chem. Solids (in the press).

'Pistorius, C. W. F. T., and Snyman, H. C.. Z.phys. Chem. (in the press).

\section{Polymeric Structure of Mercury tert-Butyi Mercury Mercaptide}

INVESTIGATIONS of metal alkoxides ${ }^{1}$ have shown that polymeric molecules $\left[M(\mathrm{O} R)_{x}\right]_{n}$ are generally formed unless the alkyl group $(R)$ is bulky. Work on sulphur analogues known as metal mercaptides $M(\mathrm{~S} R)_{x}$ was undertaken in order to compare the structures and properties of metal alkoxides and metal mercaptides. A survey of the work on metal mercaptides showed that the lowest mercaptide, mercury methyl mercaptide $\mathrm{Hg}\left(\mathrm{S} \cdot \mathrm{CH}_{3}\right)_{2}$, has quite a compact structure ${ }^{2}$ having weak intermolecular $\mathrm{Hg} \rightarrow \mathrm{S}$ bonds. The structure is consistent with the high melting point $\left(185^{\circ}\right)$ and low solubility of this compound. The next higher mercaptide, mercury ethyl mercaptide $\mathrm{Hg}(\mathrm{S} \cdot \mathrm{Et})_{2}$, melts at a low temperature $\left(76^{\circ}\right)$ and as such has essentially a molecular structure ${ }^{3}$. The structures of most of the higher mercaptides are likely to be mole. cular since they are volatile and soluble in organic solvents. The properties of mercury tert-butyl mercaptide did not fit into this pattern. This compound has a low solubility and sublimes at a high temperature $\left(135^{\circ}\right)$ under low pressure. An X-ray analysis of this compound was, therefore, undertaken in order to elucidate its crystal structure.

Rotation and Weissenberg photographs (copper radiation) of the orthorhombic needles of the compound obtained by vacuum sublimation gave the following results: $a=18.36 \pm 0.03 \AA, b=9.18 \pm 0.02 \AA, c=$ $7.52 \pm 0.01 \AA ; d_{\text {obs }}=1.97 \mathrm{~g} \mathrm{~cm}^{-3}, d_{\text {calc }}=1.972 \mathrm{~g} \mathrm{~cm}^{-3}$; $z=4$; space group $C 222$. The $h k 0$ and $h 0 l$ results were obtained and measured using multiple-film technique and visual estimation.

The $(h k 0)$ and $(h 0 l)$ Patterson projections gave the co-ordinates for $\mathrm{Hg}_{1}, \mathrm{~S}_{1}$ and $\mathrm{S}_{2}$ and precluded the other two space-groups, namely, $\mathrm{Cmm} 2$ and $\mathrm{Cmmm}$. Positions of the carbon atoms obtained by mercury difference Fourier syntheses are less precise because of the presence of the heavy mercury atom in the crystal structure. The structure was refined by the successive differ. ence Fourier syntheses and the final agreement index for all $h k 0$ and $h 00$ reflexions is $0 \cdot 12$. All calculations were made on the IBM 7040 computer using programmes written in Fortran $I V$, in this laboratory.

The results of the structure analysis of this compound are interesting. The structure of this compound is quite different from those of the other known mercaptides and consists of rows of mercury atoms $(\mathrm{Hg}-\mathrm{Hg}=3.76 \pm$ $0.01 \AA)$ parallel to the crystallographic $C$ axis. Each mercury is surrounded by four sulphur atoms $(\mathrm{Hg}-\mathrm{S}=$ $2.59 \pm 0.025 \AA, 2.66 \pm 0.025 \AA$ ) in a highly distorted tetrahedral arrangement, angles SHgS being $87 \pm 1.5^{\circ}$, $90 \pm 1 \cdot 5^{\circ}, 121 \pm 1 \cdot 5^{\circ}$. A polymeric chain parallel to the $C$ axis is formed by an infinite sharing of the opposite edges of the tetrahedra. The sulphur of the mercapto group acts as a bridge linking the two neighbouring atoms. The values of the $\mathrm{Hg}-\mathrm{S}-\mathrm{Hg}$ bridge angles are $90 \pm 1.5^{\circ}$

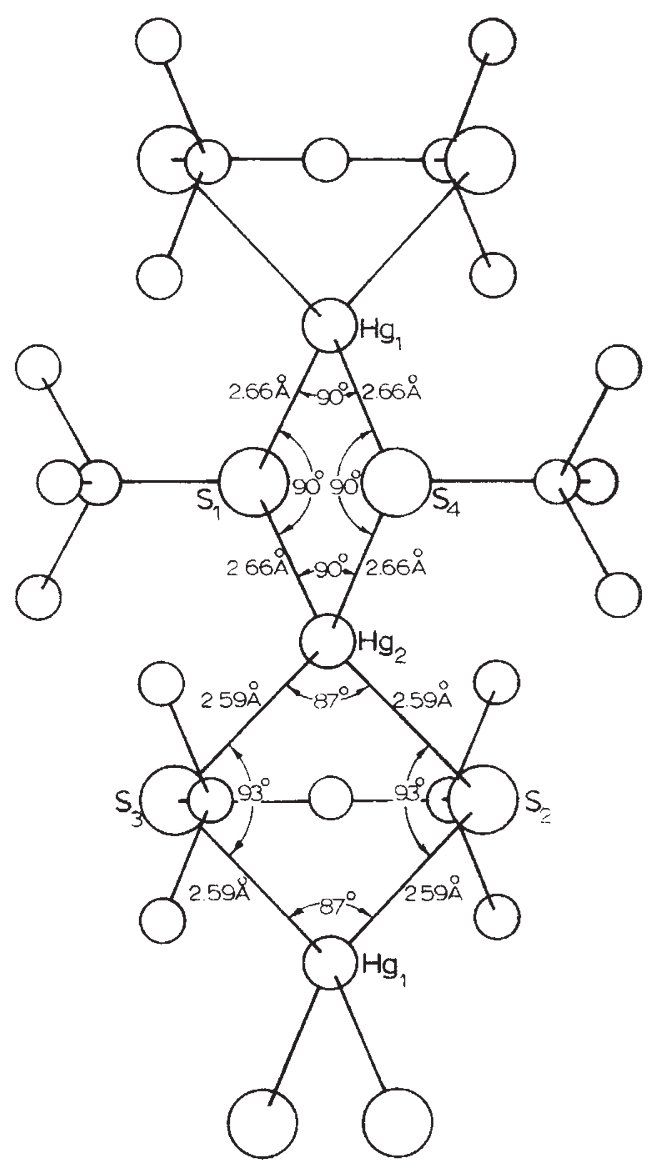

Fig. 1. Bond-lengths and bond-angles in the polymeric chain of mercury tert-butyl mercaptide

and $93 \pm 1 \cdot 5^{\circ}$. The dimensions of the chain are shown in Fig. 1. All chains are parallel to each other and to the $C$ axis. The forces between the various chains are of residual type.

It is intriguing that this compound has a true polymeric structure while the lower mercaptides $\mathrm{Hg}(\mathrm{S} \cdot \mathrm{Met})_{2}$ and $\mathrm{Hg}(\mathrm{S} \cdot \mathrm{Et})_{2}$ have molecular structures. A probable explanation for this is that in all these compounds coordination occurs through sulphur, and in the case of sulphur, the greater the substitution, the greater is its co-ordinating power ${ }^{4}$.

\section{N. R. KuNChUR}

Department of Chemistry,

University of Western Ontario, London, Ontario.

'Bradley, D. C., Prog. Inorg. Chem., 2, 303 (1960).

Bradley, D. C., and Kunchur, N. R., J. Chem. Phys, 8, 2258 (1964).

'Bradley, D. C., and Kunchur, N. R. (unpublished results).

4 Martel, A. E., and Calvin, M., Chemistry of Metal Chelate Compounds, 1,0 (Prentice Hall, Inc., 1952).

\section{Optical Rotatory Power of DNA and of its Complex with Acridine Orange under Streaming Conditions}

THIs communication reports the results of experiments in which left- and right-circularly polarized light is propagated along the flow lines of a streaming solution of DNA or of the DNA-AO (acridine orange (I) ) complex, and the differential molar extinction coefficient $\left(\varepsilon_{t}-\varepsilon_{r}\right)$ is measured as a function of wave-length. By these means circular dichroism bands due to electronic trans itions polarized parallel and perpendicular to the helix 